\title{
Volume Variation Process of High-Density Polyethylene During Tensile and Creep Tests
}

\author{
F. Addiego' ', A. Dahoun' ', C. G'Sell' and J.M. Hiver' \\ 1 Laboratoire de physique des matériaux (UMR CNRS 7556), École des Mines, INPL, Parc de Saurupt, 54042 Nancy - France \\ e-mail: addiego@mines.inpl-nancy.fr - dahoun@mines.inpl-nancy.fr - gsell@mines.inpl-nancy.fr - hiver@mines.inpl-nancy.fr
}

\begin{abstract}
Résumé - Processus de la variation volumique du polyéthylène à haute densité au cours d'essais de traction et de fluage - Des éprouvettes de polyéthylène à haute densité ont été soumises à des essais de traction et des tests de fluage à l'aide d'un dispositif d'essais mécaniques à pilotage vidéométrique (VidéoTraction ${ }^{\circledR}$ ). L'évolution du volume spécifique de ce polymère semi-cristallin est caractérisée en fonction de la déformation vraie. Dans le stade élastique, on mesure une expansion hydrostatique puis, dans le stade plastique, on note une compétition entre un effet de compaction et un phénomène de dilatation. La compaction, sans doute surestimée dans les expériences, est toutefois un mécanisme important dû à l'orientation des chaînes amorphes au cours de l'étirage. Ce phénomène est attesté par des mesures de diffraction des rayons $\mathrm{X}$ qui montrent une réduction de la distance moyenne entre les chaînes amorphes. Le processus de dilatation s'explique par la diminution du taux de cristallinité et par la formation, la croissance et la coalescence de craquelures au sein et entre les sphérolites. L'observation d'échantillons déformés par microscopie électronique révèle ces défauts. La compétition compaction/dilatation est dictée par la mobilité de la phase amorphe influencée elle-même par la température et le temps.
\end{abstract}

\footnotetext{
Abstract - Volume Variation Process of High-Density Polyethylene During Tensile and Creep Tests - Samples of high-density polyethylene have been subjected to tensile tests and creep experiments by means of a video-controlled testing system (VidéoTraction ${ }^{\odot}$ ). The evolution of specific volume in this semi-crystalline polymer is determined versus true strain. In the elastic stage, we measure a hydrostatic expansion and then, in the plastic stage, we observe a competition between a compaction effect and a dilatation phenomenon. Although compaction is probably overestimated in the present testing technique, it represents a pertinent mechanism that is ascribed to the orientation of the amorphous chains during stretching. This phenomenon is characterized by X-ray diffraction measurements that show a reduction of average distance between amorphous chains. Dilatation process is explained by the diminution of crystallinity and by the formation, growth and coalescence of crazes inside and between spherulites. Electron microscopy reveals these defects. The competition between compaction and dilatation, controlled by the mobility of the amorphous phase, depends on temperature and time.
} 


\section{INTRODUCTION}

Deformation damage, characterized by volume changes induced by plasticity, has always been the object of an active debate among the community of polymer researchers. Not only the identification of voiding mechanisms at various scales is of major scientific interest, but also the quantitative modeling of cavitation rate is technologically important for the optimization of structural polymers.

Several techniques were developed to measure volume strain of polymeric samples in real time during mechanical tests, with significant improvements in terms of flexibility and precision. Pioneer systems were essentially based on fluid dilatometers $[1,3]$ but their performances were rather limited because they only gave access to global volume changes and were very sensitive to temperature fluctuations. Another family of systems utilized multiaxially disposed mechanical extensometers but:

- they were complicated to manipulate;

- they caused unwanted indentation at the surface of soft polymers;

- they were generally limited to low temperatures [4, 8-10, 13].

Although the above techniques are still applied by some researchers, the computerized video techniques developed during the last decade brought a decisive contribution to the assessment of volume strain in polymers. Originally, they were limited to the pre-necking deformation stage $[12,14-$ 17]. However, the novel video-controlled testing system that was recently developed in this laboratory has several interesting features [18]:

- it provides in real time the true stress/strain behavior locally within a representative volume element (RVE) situated at the center of the neck;

- it gives access to the volume strain in the same RVE;

- it allows the user to regulate dynamically either true strain rate (for tensile tests) or true stress (for creep tests).

Characterization of microstructural mechanisms has also been the object of many papers [5-9]. While the elastic volume strain was simply modeled on the basis of Poisson's ratio, $v$ $[10,11]$, it was shown that the important dilatation of polymers under stretching is essentially due to the formation of voids in the amorphous layer between crystalline lamellae [12].

The objective of this study is to apply the video-controlled system to high density polyethylene (HDPE), considered as a model semi-crystalline polymer, and to correlate the volume variation with microstructural mechanisms. An important feature of the method is that the method remains applicable after necking occurred, opening the way to the large strains range. Tensile and creep tests are performed under different experimental conditions. Microstructural evolution is analyzed after unloading and recovery at different strains during tensile tests. Characterization includes scanning electron microscopy and wide-angle X-ray scattering. Experimental information is interpreted in a deformation scheme taking into account the concurrence of shear and cavitation processes in plastic deformation.

\section{EXPERIMENTAL}

\subsection{Material}

The HDPE investigated in this work was manufactured by DuPont (Canada) under the reference Sclair 2907. Its number and weight average macromolecular weights, determined by previous authors [19] are equal to $\bar{M}_{n}=16800 \mathrm{~g} / \mathrm{mol}$ and $\bar{M}_{w} 93600 \mathrm{~g} / \mathrm{mol}$, respectively. Cylinders $110 \mathrm{~mm}$ in diameter were extruded by the Plastifab Company of Montréal (Canada). Analysis of the material by differential scanning calorimeter (DSC) gives access to the index of crystallinity, $X_{c w}=77 \mathrm{wt} \%$, to the melting temperature, $T_{m}=136^{\circ} \mathrm{C}$ and to the average crystallite thickness, $\mathrm{L}=12.6 \mathrm{~nm}$. Dynamic mechanical analysis (DMA) at a frequency of $1 \mathrm{~Hz}$ indicates the glass transition temperature, $T_{g}=-113.5^{\circ} \mathrm{C}$. Hydrostatic weighting provides the density, $\rho=0.962 \mathrm{~g} / \mathrm{cm}^{3}$. Microscopic observation shows that the material is characterized by a spherulitic morphology with regularly twisted lamellae.

\subsection{Mechanical Tests}

Plates of thickness $7 \mathrm{~mm}$ were sawn out of the cylinders parallel to the axis. Samples were machined in these plates with overall dimensions of $90 \times 16 \times 6 \mathrm{~mm}^{3}$. A geometric defect was milled in the center of the above specimens with a large radius of curvature until the smallest cross-section is equal to $6.8 \times 6 \mathrm{~mm}^{2}$.

Uniaxial tensile tests and creep tests are carried out on a universal traction machine MTS 810 . With the tensile samples described above, the deformation localizes in the central region. With the video system utilized here (VidéoTraction ${ }^{\circledR}$, Apollor SA, Lunéville, France) the mechanical variables are determined by analyzing the displacements of seven dot markers printed on the main face of the specimens with a proprietary fluorescent painting, prior to deformation. Five markers $A, B, C, D, E$ are aligned along the tensile axis $x_{3}$ and three markers $F, C, G$ are aligned along the transversal axis $x_{1}$ (Fig. 1). The position of each dot is assessed through the coordinates $\left(x_{1}, x_{3}\right)$ of its center of gravity. The representative volume element investigated is a virtual slice of material, with a thickness of $0.2 \mathrm{~mm}$, situated at the smallest crosssection. The following variables are simultaneously determined in this RVE while the sample is stretched: axial true strain, transverse true strain, axial true strain rate and axial true stress. From the displacement of each dot in the longitudinal group, the system calculates four axial Hencky strains, $\varepsilon_{33}^{A B}=\ln \left(A B / A_{o} B_{o}\right), \quad \varepsilon_{33}^{B C}=\ln \left(B C / B_{o} C_{o}\right)$, 
$\varepsilon_{33}^{C D}=\ln \left(C D / C_{o} D_{o}\right), \varepsilon_{33}^{D E}=\ln \left(D E / D_{o} E_{o}\right)$ and two transverse Hencky strains from the displacements of dots in the transverse group, $\varepsilon_{11}^{F C}=\ln \left(F C / F_{o} C_{o}\right)$ and $\varepsilon_{11}^{C G}=\ln \left(C G / C_{o} G_{o}\right)$. The axial true strain in the RVE, $\varepsilon_{33}$, is obtained from a polynomial interpolation of the four axial strains $\varepsilon_{33}^{A B}, \varepsilon_{33}^{B C}, \varepsilon_{33}^{C D}, \varepsilon_{33}^{D E}$, and the transverse true strain in the same RVE is the average value $\varepsilon_{11}=\left(\varepsilon_{11}^{F C}+\varepsilon_{11}^{C G}\right) / 2$. The volume strain in the RVE is the sum of the principal strains $\varepsilon_{v}=\ln \left(V / V_{\mathrm{o}}\right)=\varepsilon_{11}+\varepsilon_{22}+\varepsilon_{33}$. Here we consider that the two transverse strains along specimen width, $\varepsilon_{11}$, and thickness, $\varepsilon_{22}$, are equal under the assumption of transversal symmetry. The appropriate stress definition associated with Hencky strain is the Cauchy stress (also called "axial true stress"). It takes into account the reduction of the cross-sectional area, $S<S_{o}$, undergone by the specimen while it is stretched: $\sigma_{33}=F / S_{o} \times \exp \left(\begin{array}{ll}-2 & \varepsilon_{11}\end{array}\right)$. More details on the experimental device and on the determination of the strains have been described elsewhere [18, 20].

Tensile tests are run at different temperatures for a given strain rate of $10^{-3} \mathrm{~s}^{-1}$ and at different strain rates for a given temperature of $40^{\circ} \mathrm{C}$. Creep tests are run at different stresses for a given temperature of $40^{\circ} \mathrm{C}$. Volume strain is characterized during unloading and recovery after tensile tests performed at ambient temperature under a strain rate of $10^{-3} \mathrm{~s}^{-1}$.

\subsection{Microstructural Characterization}

Microstructure is observed by scanning electron microscopy (SEM) for different residual strain in the RVE on cryofractured surfaces obtained by fragile rupture of notched samples immersed in liquid nitrogen for 10 minutes. The microscope is a Philips FEG XL 30. Before observation, the samples are coated with a gold layer. Amorphous phase is characterized by wide-angle X-ray scattering (WAXS) by means of a 2D diffraction system (Inel, France) equipped with a copper anode $\left(\lambda K_{\alpha 1}=0.154 \mathrm{~nm}\right)$. The point of incidence of the incident X-ray beam on the specimen is adjusted precisely at the center of the neck by means of a laser system. We analyze the diffracted intensity distribution in the amorphous halo, $\mathrm{I}(\phi, 2 \theta)$. For each inclination angle, $\phi$, the diffraction angle at maximum intensity, $2 \theta_{\max }$, gives access to an equivalent Bragg's distance, $\mathrm{d}(\phi)=\lambda / 2 \sin \left(\theta_{\max }\right)$ $[21,22]$. The average Bragg's distance, $\langle\mathrm{d}\rangle$, is obtained by integration of $\mathrm{d}(\phi)$ over the whole range of inclination angles. This distance is presumably representative of local packing of the macromolecular chains in the amorphous phase.

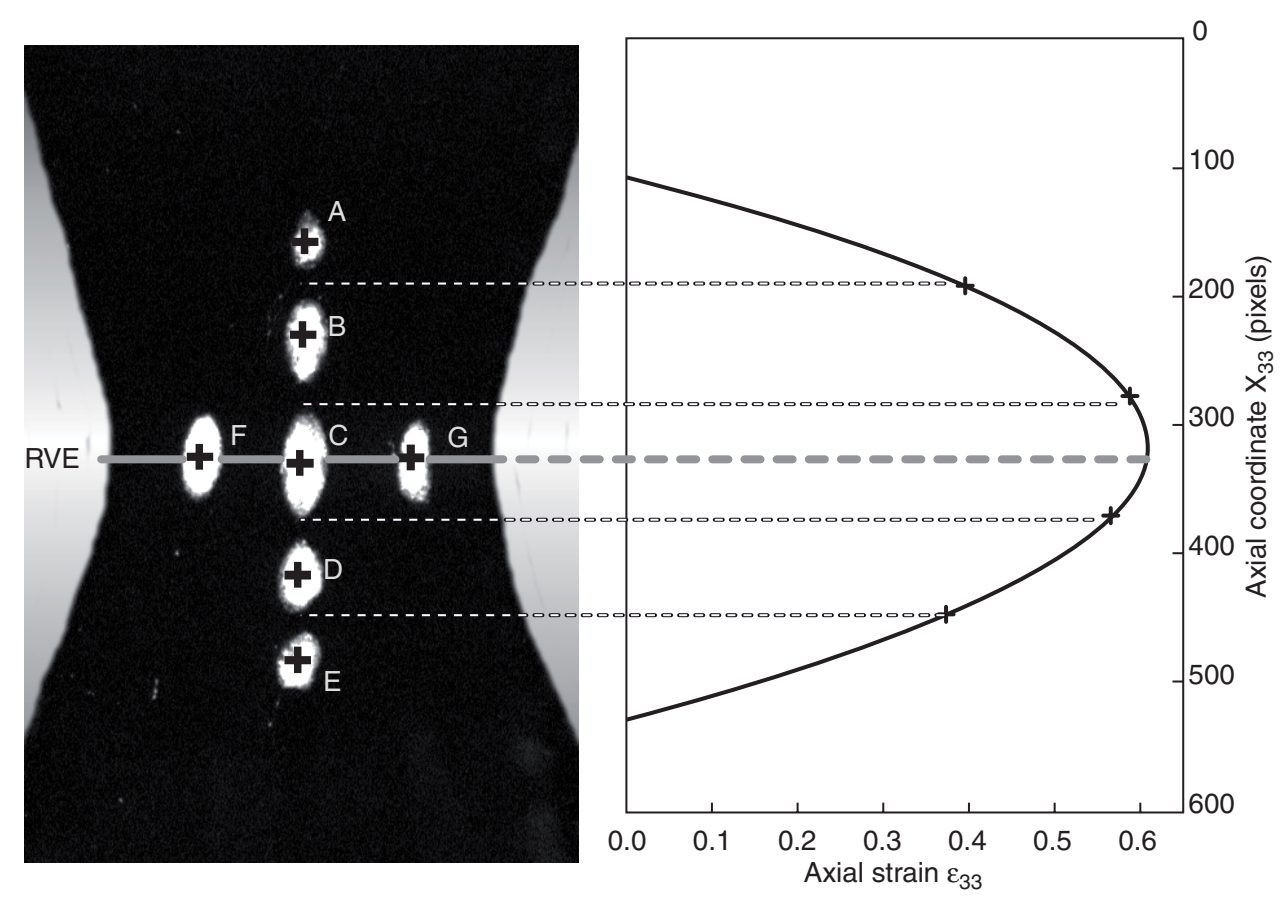

Figure 1

Determination of true axial strain in the representative volume element. 


\section{RESULTS}

\subsection{Tensile Tests}

\subsubsection{Material Behavior During Monotonous Loadings}

The curves in Figure 2 show the influence of strain rate and temperature on the response of HDPE to large strains under uniaxial tension. When temperature increases or when strain rate decreases, one notes a significant decrease of yield stress $\sigma_{y}$. The recorded values of the yield stress, $\sigma_{y}$, are between $23.9 \mathrm{MPa}\left(\right.$ at $\mathrm{T}=40^{\circ} \mathrm{C}$ and $\dot{\varepsilon}_{33}=1.10^{-3} \mathrm{~s}^{-1}$ ), and 29.8 $\mathrm{MPa}$ (at $23^{\circ} \mathrm{C}$ and $1.10^{-3} \mathrm{~s}^{-1}$ ). During the plastic stage, a continuous strain hardening is observed except at $\dot{\varepsilon}_{33}=5 \cdot 10^{-3} \mathrm{~s}^{-1}$ where the curve show strain softening followed by a weak strain hardening. The corresponding volume strain - true strain curves are displayed in Figure 2. As shown before $[10,11]$, the dilatation in the elastic stage is modelled in terms of hydrostatic stress and bulk modulus $\left(\varepsilon_{v}=\sigma_{33} / 3 \mathrm{~K}\right)$, or alternatively expressed from the Poisson's ratio: $\varepsilon_{v}=\varepsilon_{33}(1-2 v)$. Consequently, from the curve in Figure 2, one finds $v=0.39$. The evolution of volume strain under larger strains differs with experimental conditions. Monotonous dilatation is observed for $\mathrm{T}=23^{\circ} \mathrm{C} / \dot{\varepsilon}_{33}=1.10^{-3} \mathrm{~s}^{-1}$ and $\mathrm{T}=40^{\circ} \mathrm{C} / \dot{\varepsilon}_{33}=5.10^{-3} \mathrm{~s}^{-1}$, volume strain reaching $\varepsilon_{v}=0.59$ and 0.32 , respectively, at $\varepsilon_{33}=1.50$. By contrast, for $\mathrm{T}=40^{\circ} \mathrm{C} / \dot{\varepsilon}_{33}=1.10^{-3} \mathrm{~s}^{-1}$, volume strain evolution shows compaction and dilatation successively. The extreme compaction, $\varepsilon_{v}=-0.026$, is measured at $\varepsilon_{33}=0.33$. Ultimately, the dilatation reaches $\varepsilon_{v}=0.27$ at $\varepsilon_{33}=1.5$.

\subsubsection{Material Behavior During Unloading and Recovery Stages}

In Figure 3, we display the recovery of $\varepsilon_{33}$ and $\varepsilon_{v}$ for a specimen subjected to a tensile test carried out at $\mathrm{T}=23^{\circ} \mathrm{C} /$ $\dot{\varepsilon}_{33}=1.10^{-3} \mathrm{~s}^{-1}$, subsequently unloaded from $\varepsilon_{33}=1.0$, and eventually left to recover at zero stress for a period of 3 hours. It is noted that axial strain and volume strain decrease rapidly during the unloading sequence (b to c) and more and more slowly during the recovery sequence (c to d). The recovery process under zero stress is due to the progressive spring back of the amorphous chains that are mobile at room temperature. It needs to be taken into consideration for the evaluation of the actual strain state in stretched samples whose microstructure is characterized by X-ray diffraction (WAXS) and scanning electron microscopy (SEM). Although previous authors showed that extensive shrinkage was obtained after several months at room temperature [23] or several hours at temperatures higher than $120^{\circ} \mathrm{C}$ [24], the recovery saturates rapidly in our experiments. In particular, we verified that that $\varepsilon_{33}$ and $\varepsilon_{v}$ did not change significantly any more in the period between 3 hours and 24 hours after unloading the samples. Since the WAXS and SEM characterization of stretched samples was performed in a delay after unloading that never exceeded 24 hours, the above property ensures that the features revealed by these samples correspond to the "residual strains" $\left(\varepsilon_{33 r}\right.$ and $\left.\varepsilon_{\mathrm{vr}}\right)$ systematically determined after the nominal delay of 3 hours. The complex curve in Figure 4 shows that, for increasing strains followed by unloading and relaxation, the relative variations of volume strain and true strain between the loaded state and the relaxed state decrease gradually. For example, at $\varepsilon_{33}=0.2$, axial and volume strains
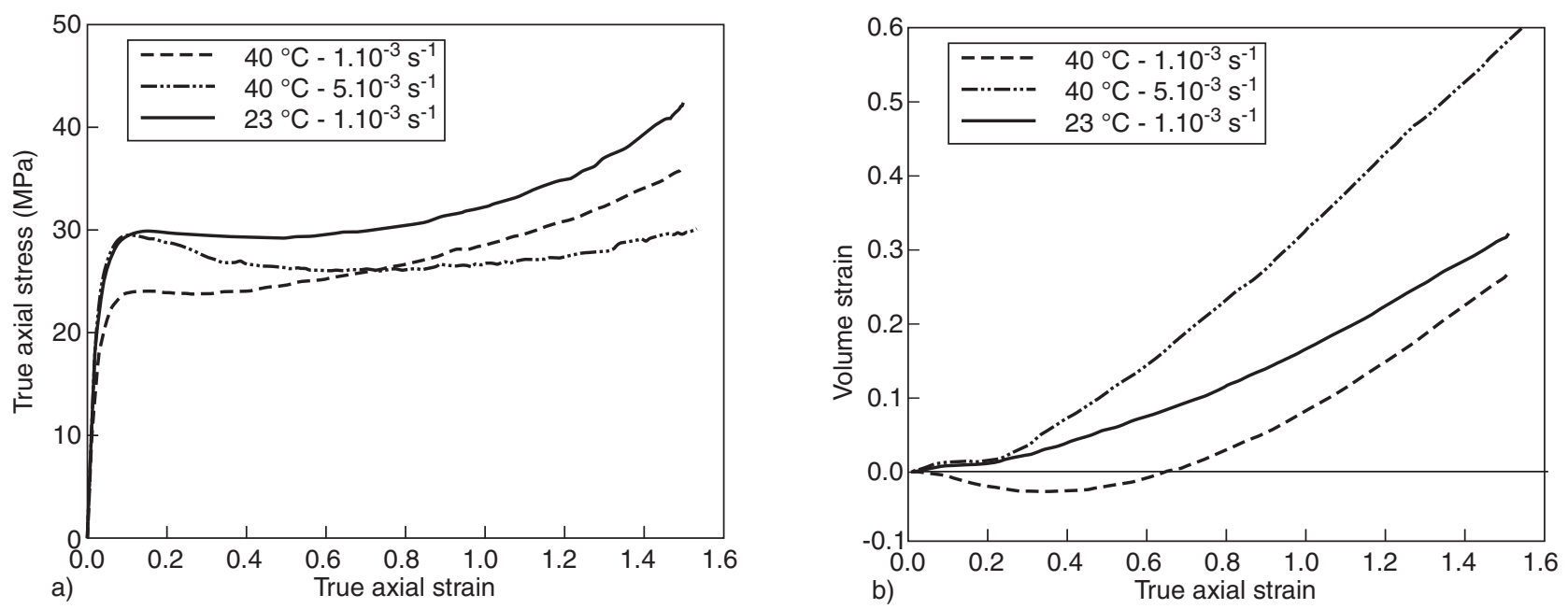

Figure 2

Mechanical behavior of HDPE under tensile testing. 

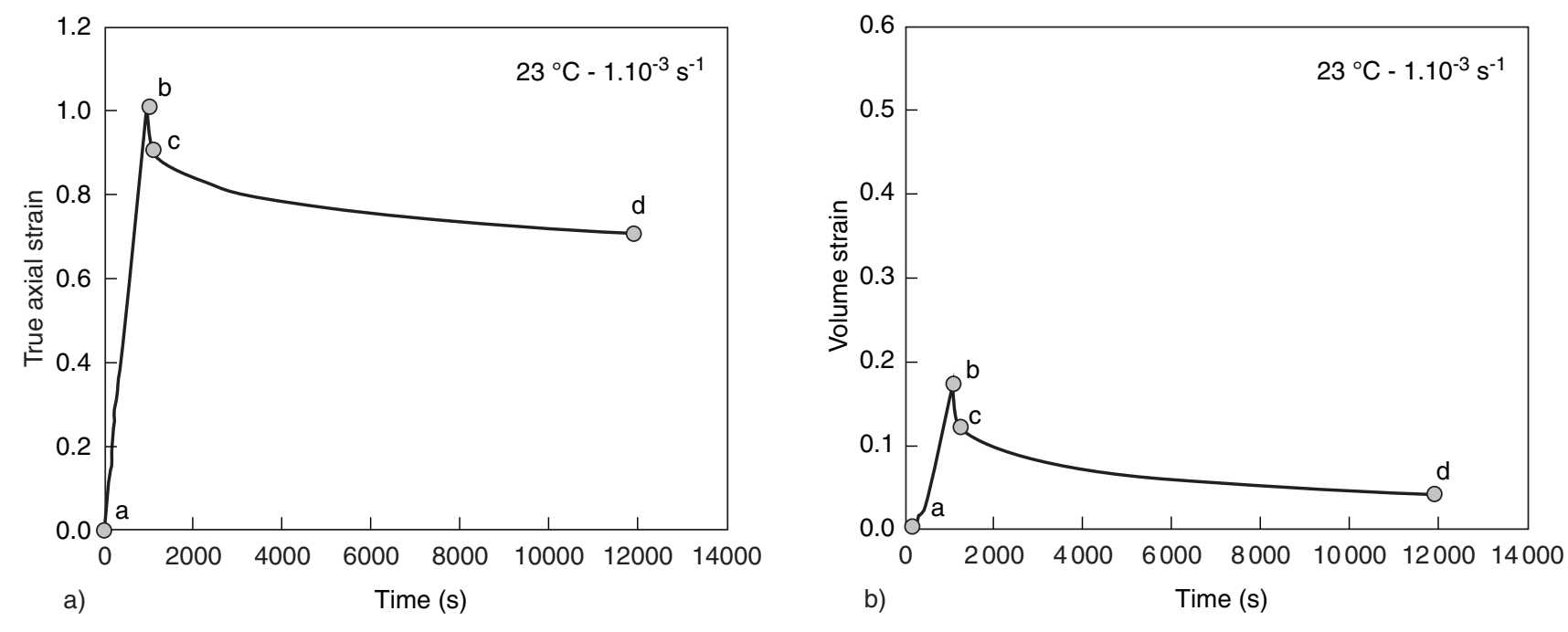

Figure 3

True stress - time and volume strain - time curves of HDPE during a monotonous load until the strain $\mathrm{e}_{33}=1.0(\mathrm{a}-\mathrm{b})$, unloading stage $(b-c)$ and 3 hours recovery process $(c-d)$.

decrease by $128 \%$ and $74 \%$ respectively after maximum recovery, while corresponding values of $41 \%$ and $12 \%$ are recorded at $\varepsilon_{33}=1.5$. After recovery, the $\varepsilon_{v r} v s$. $\varepsilon_{33 r}$ envelope (black dots in Fig. 4) does not show the elastic dilatation any more, but the compaction stage is more pronounced than under load, residual volume strain attaining -0.02 for $\varepsilon_{33 r}=0.14$. At large residual axial strains, large residual dilatation is measured $\left(\varepsilon_{v r}=0.18\right.$ for $\left.\varepsilon_{33 r}=1.3\right)$.

\subsection{Creep Tests}

The creep experiments presented in Figure 5 were performed at $40^{\circ} \mathrm{C}$ under constant true stresses corresponding to $40 \%$, $50 \%$ and $60 \%$ of the yield stress undergone by the HDPE when tensile tested under a strain rate of $5 \cdot 10^{-3} \mathrm{~s}^{-1}$. After the instantaneous elastic deformation recorded as stress is rapidly applied, the evolution of true strain versus creep time shows two successive stages:

- primary creep with a decreasing axial strain rate;

- secondary creep with a constant strain rate.

Under higher stress, one notes a faster increase of strain rate in primary creep and an earlier onset of secondary creep. As for the $\varepsilon_{v} v s$. time curves, they show also two stages after elastic dilatation:

- plastic compaction at moderate strains;

- ultimate dilatation.

One observes that the compaction process increases as the applied stress is increased from 11.6 MPa to 14.5 MPa and then, it decreases from 14.5 MPa to 17.4 MPa. The extreme compaction, $\varepsilon_{v}=-0.06$, is recorded for $\sigma_{33}=14.5 \mathrm{MPa}$ for $t=10000 \mathrm{~s}$. A rapid dilatation is observed under 17.4 $\mathrm{MPa}$ after a short compaction stage, $\varepsilon_{v}$ reaching 0.09 after $20000 \mathrm{~s}$.

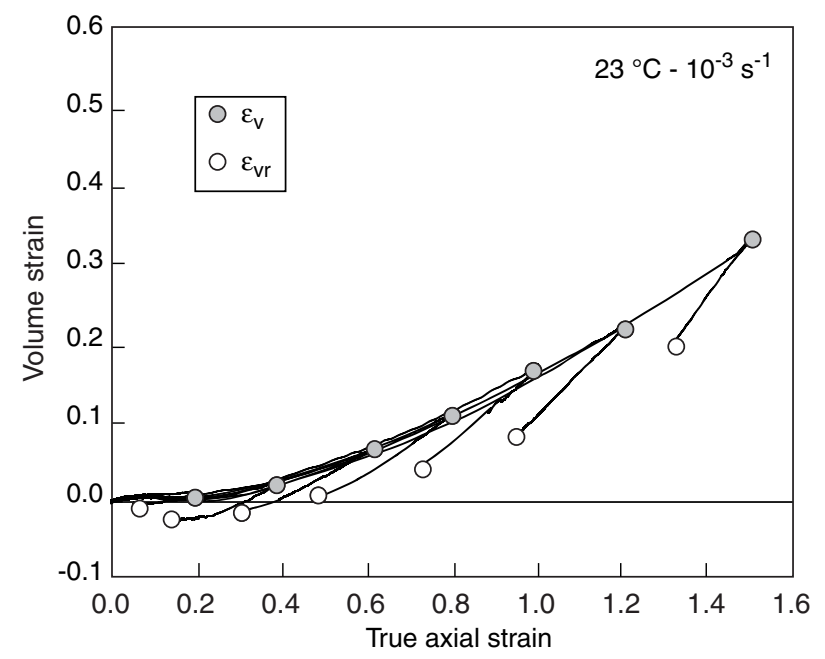

Figure 4

Volume strain $v s$. true strain of HDPE under growing tensile loads followed by unloading and recovery stage.

\subsection{SEM Investigation}

Evolution of HDPE microstructure with residual strain is shown in Figure 6. The non-deformed state is characterized by a set of micro-cracks leading to a blocky structure. Microcracks are constituted by ridges corresponding to microdomains deformed during the propagation of micro-cracks [25]. For a residual strain $\varepsilon_{33 r}=0.29$, one notes the occurrence of cavitation. The biggest cavities correspond to crazes that are known to grow through fibrillation of the polymer. When residual strain increases, cavitation phenomena are amplified. Evidence of craze coalescence is acknowledged 

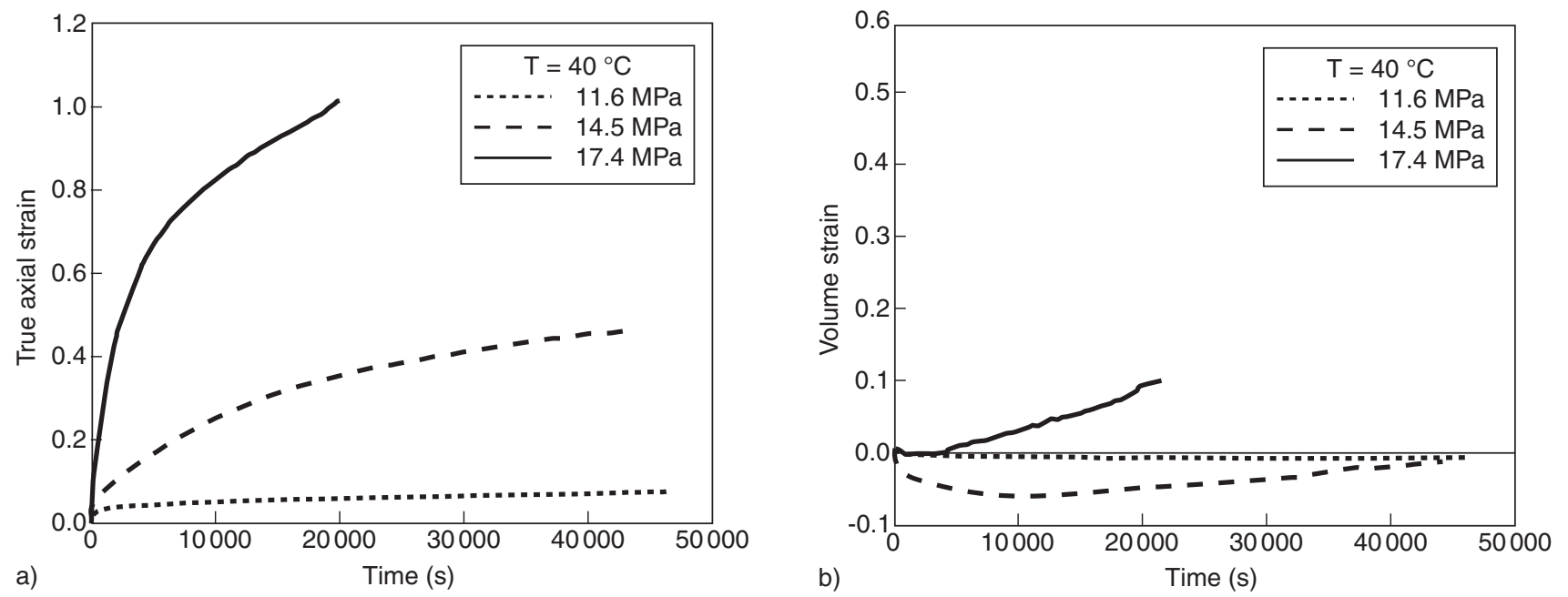

Figure 5

Constant stress creep tests on HDPE at $40^{\circ} \mathrm{C}$.

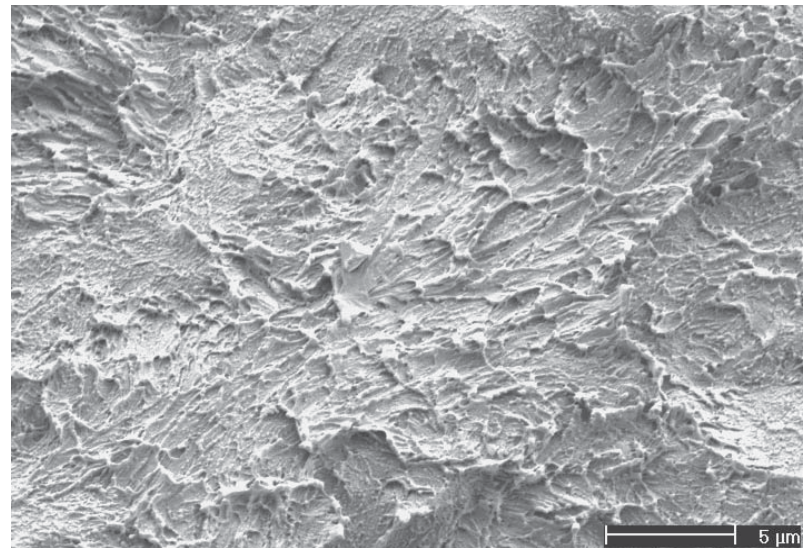

a) $\varepsilon_{33 r}=0 ; \varepsilon_{v r}=0$

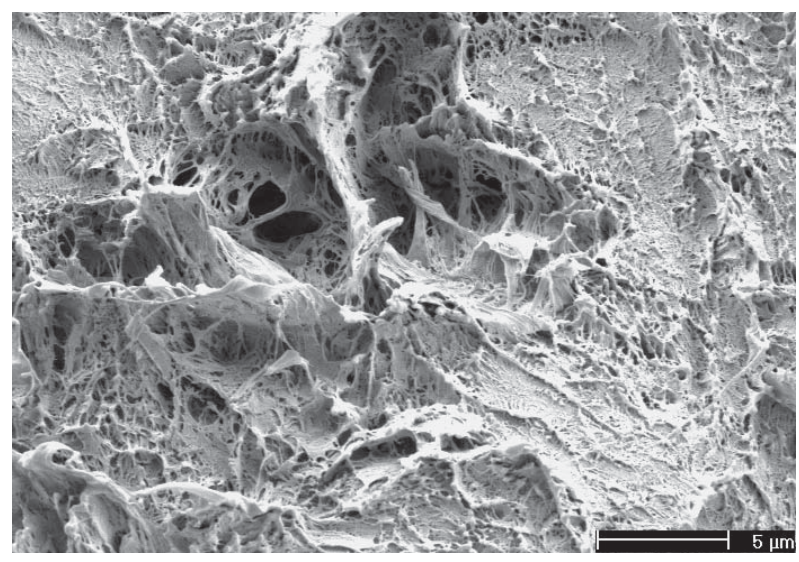

c) $\varepsilon_{33 \mathrm{r}}=0.48 ; \varepsilon_{\mathrm{vr}}=0.005$

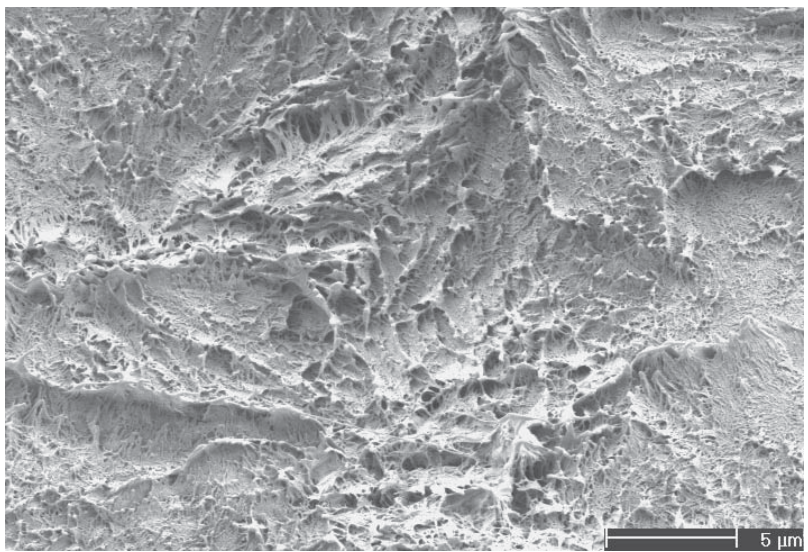

b) $\varepsilon_{33 r}=0.29 ; \varepsilon_{\mathrm{vr}}=-0.014$

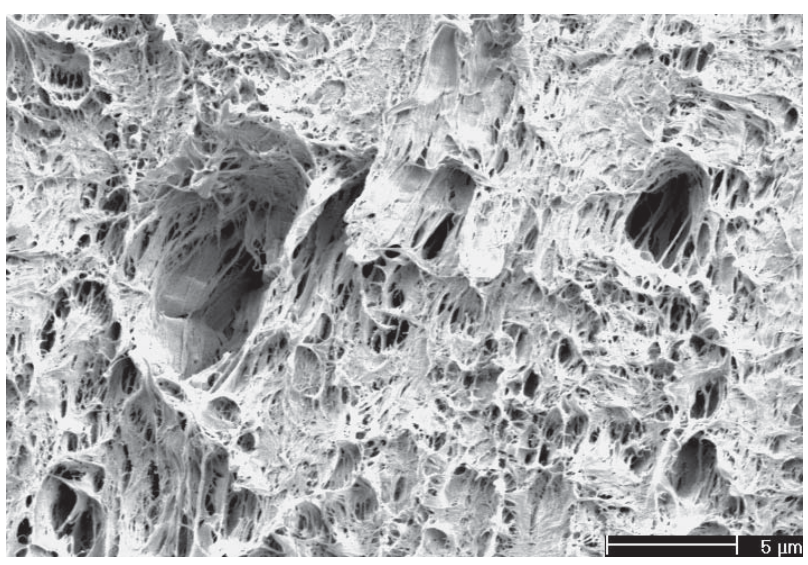

d) $\varepsilon_{33 \mathrm{r}}=1.3 ; \varepsilon_{\mathrm{vr}}=0.18$

Figure 6

SEM observation of cryo-fractured surface with various residual strains (vertical tensile direction). 

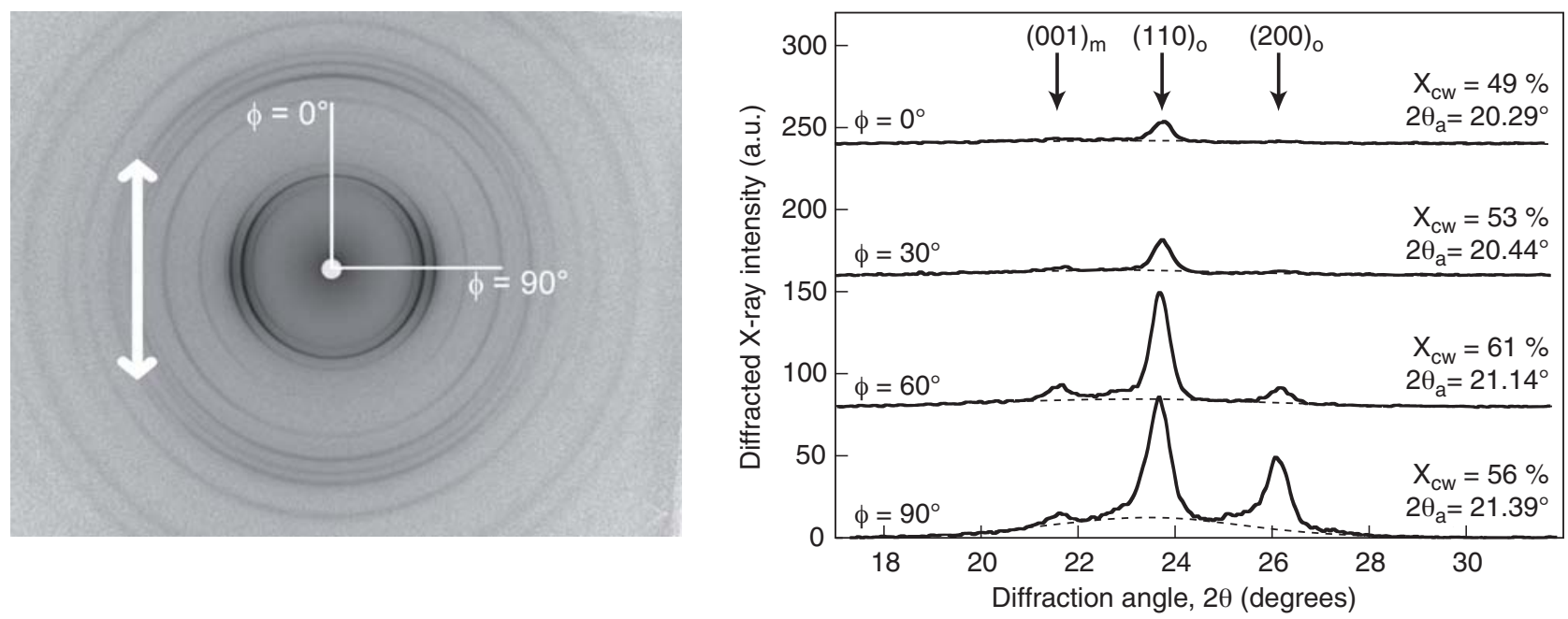

Figure 7

Diffraction plate $\mathrm{I}(\phi, 2 \theta)$ and examples of $\mathrm{I}(2 \theta)$ scans for a residual strain $\varepsilon_{33 r}=0.48$.

by the observation of superimposed cavities for $\varepsilon_{33 r}=0.48$. The residual volume strain $\varepsilon_{v r}=0.18$ is characterized by the orientation of cavities toward the tensile direction.

\subsection{X-ray Diffraction}

The diffraction pattern $\mathrm{I}(\phi, 2 \theta)$ and various scans $\mathrm{I}(2 \theta)$ corresponding to a residual strain $\varepsilon_{33 r}=0.48$ are represented in Figure 7. The non-homogeneity of diffraction rings denotes the strain-induced orientation of crystallized chains. This orientation phenomenon is also shown in the different scans $\mathrm{I}(2 \theta)$ where the peaks corresponding to the $(001)_{m}$, $(110)_{o}$ and $(200)_{o}$ planes (monoclinic and orthorhombic systems) and the amorphous halo are identified. From $\phi=0$ to 90 degrees, a reinforcement of the intensity of crystalline peaks and amorphous halo is observed. Consequently, these planes and the amorphous diffraction entities rotate towards tensile direction. The diffraction patterns provide two interesting pieces of information. Firstly we determine the weight-based degree of crystallinity, $X_{c w}$, which is classically determined by the relative surface peak of the amorphous bump, after integration over the azimuth angles. The result of this computation is displayed in Figure 8. It is noted that the degree of crystallinity decreases dramatically, from $73 \%$ to $53 \mathrm{wt} \%$. Secondly, the diffraction analysis provides information on the local order in the amorphous phase through the variation of the diffraction angle, $2 \theta_{a}$, at the top of the amorphous bump. Unexpectedly, it is noted that $2 \theta_{a}$ is systematically larger in the deformed PE than in the original material and depends on the azimuth angle. It is nearly equal to the value of the non-deformed material for $\phi=0$ and maximum for $\phi=90$ degrees. This result shows that the Bragg's distance between chains oriented parallel to stretching direction is $\mathrm{d}=0.415 \mathrm{~nm}$. The evolution of average intermolecular distance $\langle d\rangle v s$. residual strain is showed in Figure 8. At the non-deformed state, $\langle\mathrm{d}\rangle=0.428 \mathrm{~nm}$. A rapid decrease of $\langle\mathrm{d}\rangle$ is observed until the residual strain reaches 0.2. Subsequently, the decrease of $\langle\mathrm{d}\rangle$ is slower. When $\varepsilon_{33 r}=1.30,\langle\mathrm{~d}\rangle=0.417 \mathrm{~nm}$ which indicates a $2.6 \%$ decrease of $\langle d\rangle$ compared to the nondeformed state.

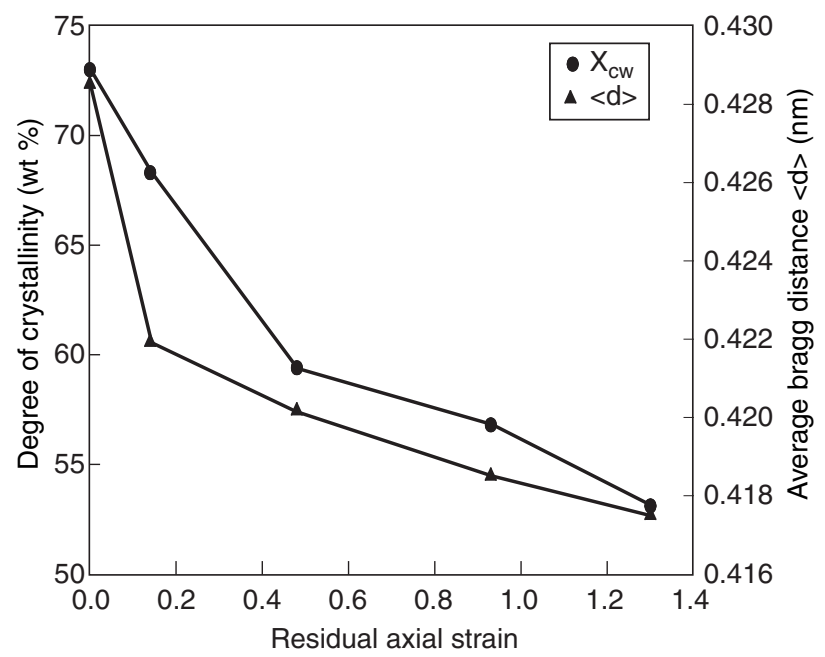

Figure 8

Evolution of weight-average degree of crystallinity, $X_{c w}$, and average inter-chain distance, $\langle d\rangle$, vs. residual strain, $\varepsilon_{33 r}$. 


\section{DISCUSSION}

As shown above, the volume strain experienced by HDPE is due to the combination of elastic dilatation, plastic compaction and damage dilatation. The first phenomenon, caused by the effect of hydrostatic stress on the van der Waals bonded material, is out of the scope of this work. In the three sections that follow, we will discuss more particularly the pertinence of the compaction effect. Finally we will analyze briefly the damage dilatation mechanisms.

\subsection{Bibliographic Data on Compaction Amplitude}

The compaction phenomenon was much less documented than the other processes and is much more controversial as for its absolute amplitude and underlying mechanisms.

Powers and Caddell [3] assessed volume variation of PE with mechanical extensometers during tensile tests at ambient temperature under a stretching rate equal to $0.05 \mathrm{~cm} / \mathrm{min}$. They recorded a small but significant volume decrease $\left(\varepsilon_{v}=-0.002\right.$ for $\left.\varepsilon_{33}=0.09\right)$. Unfortunately, they were limited to the pre-necking stage.

Tang et al. [7] measured volume strain in PP with an axial optical extensometer and two transverse mechanical extensometers during tensile tests. They carried out the tests at ambient temperature under different strain rates. At the highest strain rates, they invariably observed a dilatation. When strain rate decreases, they noted a small compaction effect before ultimate dilatation. The maximum compaction effect obtained was $\varepsilon_{v}=-0.01$ for $\varepsilon_{33}=0.09$ under $8.5 \times 10^{-3} \mathrm{~s}^{-1}$.

Gaucher-Miri et al. [15] studied volume variation in a low-density ethylene/butene copolymer with a multiaxial video extensometer during tensile tests performed at $20^{\circ} \mathrm{C}$ for a stretching rate of $0.5 \mathrm{~mm} / \mathrm{min}$. Like in our study, they noted a net volume compaction at the beginning of deformation, followed by volume strain increase at higher strains. The minimum volume strain was $\varepsilon_{v}=-0.03$ for $\varepsilon_{33}=0.6$. Positive volume strain was found for $\varepsilon_{33}>2.0$.

Negative volume variations were observed during creep tests on semi-crystalline polymers $[4,13,26]$. Cherry and Hin [13] measured volume variation of PE using three mechanical extensometers under creep at ambient temperature. After the elastic volume expansion, these authors systematically recorded a compaction process that reached $\varepsilon_{v}=-0.017$ for $t=25000 \mathrm{~s}$ under $\sigma_{33}=17.1 \mathrm{MPa}$. Like in our results (Fig. 5), they noted that compaction increases with applied stress.

\subsection{Experimental Errors on Compaction Measurement}

Careful analysis of the VidéoTraction ${ }^{\circledR}$ method utilized in this work reveals three critical points:

- interpolation of the axial strain, $\varepsilon_{33}$, from the longitudinal dot positions;
- inhomogeneity of transverse strain across the RVE;

- discrepancy between $\varepsilon_{11}$ and $\varepsilon_{22}$.

Concerning the first point, we found that the polynomial fit employed here underestimates the true axial strain, $\varepsilon_{33}$, by about $2.5 \%$ for acute neck profiles. As for the second point it is evident that surface strains does not correspond rigorously to the average transverse strains across the specimen section. From the analysis of samples with different distances between transverse dots, we estimate that $\varepsilon_{11}$ is underestimated (too negative) by about $6 \%$ in extreme configurations. The last point is concerned with the assumption of transverse isotropy adopted in this work. In reality, precise transverse measurements at the neck of stretched samples shows that the reduction in thickness is slightly higher than the reduction in width. Quantitatively, we found in a typical case that $\varepsilon_{22}$ was smaller than $\varepsilon_{11}$ by about $6 \%$. Since volume strain is the sum of the strains in the principal directions, $\varepsilon_{v}=\varepsilon_{11}+\varepsilon_{11}+\varepsilon_{33}$, and considering the respective errors committed on each component, one finds that $\varepsilon_{v}$ is systematically underestimated. In other terms, the actual compaction is certainly smaller than that measured via the present VidéoTraction ${ }^{\circledR}$ procedure. At that state of the investigation, we estimate that the error on the determination of $\varepsilon_{v}$ may attain $100 \%$ in extreme cases so that the actual value is between zero and the experimental value. Consequently, although the transient compaction for PE measured in the intermediate strain range is probably overestimated, the microstructural investigation confirms that it is not merely an experimental artifact. Potential methods to improve volume strain determination are in progress in this laboratory.

\subsection{Microstructural Compaction Mechanisms}

Although some authors (e.g. Powers and Caddell [3]) simply ignore the causes of the compaction they measured, many of them tried to relate this phenomenon to specific microstructural mechanisms.

Strain-induced crystallization was the first process invoked for explaining compaction, based on the higher density of crystalline phase. In the case of PP, Tang et al. [7] explained his results by the above argument without providing any experimental evidence for this allegation. On the overall, except minor strain-induced crystallization facts reported in some papers (e.g. Wade Adams et al. [27] for $\mathrm{PE})$, most authors (including us) have demonstrated that stretching semi-crystalline polymers globally leads to a decrease of crystallinity [28, 29]. Active fragmentation of the crystallites occurs while the fibrillar microstructure is progressively formed and crystallized chains are readily transferred into amorphous clusters during this destruction process. Consequently, interpreting compaction in terms of strain-induced crystallization is not relevant.

Another approach, based on the concept of amorphous phase orientation, should rather be considered. From their 
results on LDPE-co-butene, Gaucher-Miri et al. [15] invoked strain-induced reorganization of the amorphous phase in sheared interlamellar zones. This process is confirmed by dynamic mechanical analysis that reveals an important immobilization of amorphous chains in specimens stretched up to the extension for which compaction is at its maximum. This interpretation is supported by Bartczak et al. [22], who consider that chain alignment toward stretching direction in the amorphous phase tends to form of a close-packed array with a pseudo-hexagonal symmetry. It is thus probable that the decrease of interchain distances in the amorphous phase (Fig. 8) is the key process that controls the transient plastic compaction observed in PE upon stretching.

\subsection{Dilatation Mechanisms}

Concerning the ultimate dilatation phenomenon, it has been documented in details by many authors $[10,12,16]$, who ascribed it both to the destruction of crystalline order and to the development of voids. Since we found that the progressive loss of crystallinity on stretching is of the order of $30 \%$ (see Fig. 8), and considering that the density of the amorphous phase is about $15 \%$ less than that of the crystalline phase, a positive volume strain of about 0.04 is expected at the end of the test. Although significant, this value is small with respect to the total dilatation undergone by the material during the plastic stage. Consequently, plasticity-induced dilatation is due in majority to the cavitation process that has been observed in HDPE spherulites [30-35]. Voiding initially develops in equatorial regions, subsequently in diagonal regions and finally in polar regions. Crazes can also appear between spherulites due to the presence of macromolecular defects in these regions [33]. Cavitation phenomena appear to be less active at higher temperatures and lower strain-rates because chain mobility is enhanced under such conditions [12].

\section{CONCLUSIONS}

In high-density polyethylene plastic compaction and dilatation compete for the control of volume strain during stretching and creep tests. Compaction is recorded as a negative volume variation during a transient stage for moderate extension ratios. It is amplified when amorphous chains have more mobility and time to accommodate macroscopic deformation, at higher temperature and lower strain-rate. Large compaction is observed at $\mathrm{T}=40^{\circ} \mathrm{C}$ for $\dot{\varepsilon}_{33}=1.10^{-3} \mathrm{~s}^{-1}$ $\left(\varepsilon_{v}=-0.026\right.$ at $\left.\varepsilon_{33}=0.33\right)$. Due to experimental errors, the volume strain in the compaction range is somewhat underestimated, so that further improvements will be necessary to characterize this process with better precision. However, the errors do not contradict the pertinence of the compaction phenomenon that results from the strain-induced orientation of amorphous chains toward the drawing direction. Dilatation, for its part, is observed at larger strains. Large dilatation is recorded at $\mathrm{T}=40^{\circ} \mathrm{C}$ for $\dot{\varepsilon}_{33}=5.10^{-3} \mathrm{~s}^{-1}$ $\left(\varepsilon_{v}=0.59\right.$ at $\left.\varepsilon_{33}=1.50\right)$. It is due partly to progressive crystallite destruction and partly to cavitation. The same competition between compaction and dilatation is observed during creep tests under constant true stresses. Quantitative modeling of volume strain effect for various deformation paths and histories is now in progress.

\section{REFERENCES}

1 Whitney, W. and Andrews, R.D. (1967) Yielding of glassy polymers: volume effects. J. Polym. Sci. Pol. Sym., 16, 2981-2990.

2 Pampillo, C.A. and Davis, L.A. (1971) Volume change during deformation and pressure dependence of yield stress. $J$. Appl. Phys., 42, 4674-4679.

3 Powers, J.M. and Caddell, R.M. (1972) The macroscopic volume changes of selected polymers subjected to uniform tensile deformation. Polym. Eng. Sci., 12, 432-436.

4 Mallon, P.J., McCammond, D. and Benham, P.P. (1972) Strain ratio and volume change during tension and compression creep of thermoplastics. Polym. Eng. Sci., 12, 420-424.

5 Bucknall, C.B. and Clayton, D. (1972) Rubber-toughening of plastics, Part 1: creep mechanisms in HIPS. J. Mater. Sci., 7, 202-210.

6 Bucknall, C.B., Clayton, D. and Keast, E.W. (1972) RubberToughening of plastics, Part 2: Creep mechanisms in HIPS/PPO blends. J. Mater. Sci., 7, 1443-1453.

7 Tang, H.I., Hiltner, A. and Baer, E. (1987) Biaxial orientation of polypropylene by hydrostatic solid state extrusion, Part 3: Mechanical properties and deformation mechanisms. Polym. Eng. Sci., 27, 876-886.

8 Sinien, L., Lin, Y., Xiaoguang, Z. and Zongneng, Q. (1992) Microdamage and interfacial adhesion in glass bead-filled high-density polyethylene. J. Mater. Sci., 27, 4633-4638.

9 Meddad, A. and Fisa, B. (1997) Stress-strain behavior and tensile dilatometry of glass bead-filled polypropylene and polyamide 6. Appl. Polym. Sci., 64, 653-665.

10 Naqui, S.I. and Robinson, I.M. (1993) Review tensile dilatometric studies of deformation in polymeric materials and their composites. J. Mater. Sci., 28, 1421-1429.

11 Delin, M., Rychwalski, R.W., Kubat, J., Bertilsson, H. and Klason, C. (1994) Volume changes during flow of solid polymers. J. Non-Cryst. Solids, 172-174, 779-785.

12 Castagnet, S., Gacougnolle, J.L. and Dang, P. (2000) Correlation between macroscopical viscoelastic behaviour and micromechanisms in strained $\alpha$ polyvinylidene fluoride (PVDF). Mater. Sci. Eng., A276, 152-159.

13 Cherry, B.W. and Hin, T.S. (1981) Stress whitening in polyethylene. Polymer, 22, 1610-1612.

14 François, P., Gaucher, V. and Seguela, R. (1994) Local-scale analysis of the longitudinal strains in strongly necking materials by means of video-controlled extensometry. J. Phys.Condens. Mat., 6, 8959-8968.

15 Gaucher-Miri, V., Depecker, C. and Seguela, R. (1997) Reversible strain-induced order in the amorphous phase of a low-density ethylene/butene copolymer. J. Polym. Sci. Pol. Phys., 35, 2155-2159. 
16 Gloaguen, J.M. and Lefebvre, J.M. (2001) Plastic deformation behaviour of thermoplastic/clay nanocomposites. Polymer, 42, 5841-5847.

17 Quatravaux, T., Elkoun, S., G'Sell, C., Cangemi, L. and Meimon, Y. (2002) Experimental characterization of the volume strain of poly(vinylidene fluoride) in the region of homogeneous plastic deformation. J. Polym. Sci., 40, 25162522 .

18 G'Sell, C., Hiver, J.M. and Dahoun, A. (2002) Experimental characterization of deformation damage in solid polymers under tension, and its interrelation with necking. Int. J. Solids Struct., 39, 3857-3872.

19 Amornsakchai, T., Olley, R.H., Basset, D.C., Al-hussein, M.O.M., Unwin, A.P. and Ward I.M. (2000) On the influence of initial morphology on the internal structure of highly drawn polyethylene. Polymer, 41, 8291-8298.

20 Bai, S.L. and Wang, M. (2003) Plastic damage mechanisms of polypropylene/polyamide 6/polyethylene-octene elastomer blends under cyclic tension. Polymer, 44, 6537-6547.

21 Murphy, N.S., Minor, H., Bednarczyk, C. and Krimm, S. (1993) Structure of the amorphous phase in oriented polymers. Macromolecules, 26, 1712-1721.

22 Bartczak, Z., Galeski, A., Argon, A.S. and Cohen, R.E. (1996) On the plastic deformation of the amorphous component in semicrystalline polymers. Polymer, 37, 2113-2123.

23 Fotheringham, D.G. and Cherry, B.W. (1978) Strain rate effects on the ratio of recoverable to non-recoverable strain in linear polyethylene. J. Mater. Sci., 13, 231-238.

24 Castagnet, S., Girault, S., Gacougnolle, J.L. and Dang, P (2000) Cavitation in strained polyvinylidene fluoride: mechanical and X-ray experimental studies. Polymer, 41 , 7523-7530.

25 Brough, I., Haward, R.N., Healey, G. and Wood, A. (2004) Scanning electron micrographs of high density polyethylene fracture surfaces. Polymer, 45, 3115-3123.
26 Cangemi, L., Elkoun, S., G'Sell, C. and Meimon, Y. (2004) Volume strain changes of plasticized Poly(vinylidene fluoride) during tensile and creep tests. J. Appl. Polym. Sci., 91, 1784-1791.

27 Wade Adams, W., Yang, D. and Thomas, E.L. (1986) Direct visualization of microstructural deformation processes in polyethylene. J. Mater. Sci., 21, 2239-2253.

28 Glenz, W., Morosoff, N. and Peterlin, A. (1971) Density of drawn polyethylene. Polym. Lett., 9, 211-217.

29 Leung, W.P., Choy, C.L., Zongneng, Q. and Renje, W. (1988) Mechanical anisotropy in oriented linear polyethylene of various crystallinities. J. Appl. Polym. Sci., 36, 1305-1324.

30 Hay, I.L. and Keller, A. (1965) Polymer deformation in terms of spherulites. Kolloid Z. Z. Polym., 204, 43-74.

31 Petermann, J. and Schultz, J.M. (1978) Lamellar separation during the deformation of HDPE. J. Mater. Sci., 13, 50-54.

32 Haudin, J.M. (1982) Plastic deformation of semi-crystalline polymers, in Plastic deformation of amorphous and semicrystalline materials, G'Sell, C. and Escaig, B. (Eds.), EDP Sciences, Les Ulis, France.

33 Friedrich, K. (1983) Crazes and Shear bands in semi-crystalline thermoplastics, in Advances in polymer Science, Crazing in polymers, 52/53, Kausch, H.H. (Ed.), SpringerVerlag, Berlin-Heidelberg.

34 Butler, M.F. and Donald, A.M. (1997) Deformation of spherulitic polyethylene thin films. J. Mater. Sci., 32, 36753685 .

35 Aboulfaraj, M., G'Sell, C., Ulrich, B. and Dahoun, A. (1995) In situ observation of the plastic deformation of polypropylene spherulites under uniaxial tension and simple shear in the scanning electron microscope. Polymer, 36, 731-742.

Final manuscript received in November 2005 